\title{
Effect of Additive Agents on Sono-Degradation Petroleum Refinery Wastewater
}

\section{Qusay Jaffer Rasheed*}

Department of Chemical Engineering, A.C.Tech. Campus, Anna University Chennai, Chennai - 600 025, India

\begin{abstract}
The present study presents the sono-degradation petroleum refinery effluent and the influence of addition activated carbon and hydrogen peroxide on sonolysis. The sonolytic degradation was analyzed for the reduction in \% COD of the effluent and the results showed that the combination of activated carbon and hydrogen peroxide gave better results. The effect of key operating parameters, such as sonication time and $\mathrm{pH}$ on $\% \mathrm{COD}$ reduction were studied. Experiments were carried out at initial concentrations of activated carbon $(0.5,1,1.5$ and $2 \mathrm{gm})$ and activated carbon $(2 \mathrm{gm})$ with hydrogen peroxide $(50,100,150$ and $200 \mathrm{mg} / \mathrm{l})$ on sonochemcal degradation of effluent at $\mathrm{pH} 10$. This study showed that \% COD remaining was found to be found that the activated carbon at 2 grams a better read, therefore, adopted with the added along with 50,100,150 and $200 \mathrm{mg} / \mathrm{l}$ hydrogen peroxide respectively. Degradation was found to increase with increasing sonication time. In addition, as the concentration is increased. At the end of 90 min of sonication, the \% COD remaining was increases when the recycling of activated carbon increases.
\end{abstract}

Keywords: COD; Wastewater treatment; Petroleum refinery; Sonolysis; Activated carbon

\section{Introduction}

Petroleum refineries use large quantities of water and the wastewater production strongly depends on the process configuration. Refinery wastewater includes run-off water, process water and domestic water. The water is complex in composition and the BOD and COD [1] values are in the range of 150-200 ppm and 300-600 ppm, respectively. Typical petroleum refinery wastewater contains cyanide, oil, phenols, benzene, sulfide, ammonia and heavy metals. In addition, chemicals are dosed into water to control corrosion and biofouling.

Petroleum refinery employs a wide array of wastewater treatment and disposal methods, because wastes generated from these industries vary not only in composition but also in magnitude (volume). Various techniques used to treat the effluents are Fenton oxidation [2], photooxidation [3], ozonation [4], oxidation by direct attack of oxidants and electrochemical methods [5].

Sonolysis is considered as a new possibility in wastewater treatment field [6] and sonochemical decomposition of organic pollutants is resulted from the formation and collapse of high-energy cavitation bubbles. When the bubbles collapse enormous increase in both temperature and pressure occur [7], which results in pyrolytic cleavage of toxic compounds present in the wastewater. Prolonged exposure of wastewater to ultrasound enhances the generation of oxidative species and its production rate depends on temperature and pressure prevailing at the time of bubble collapse $[8,9]$. The additives such as activated carbon [10], $\mathrm{H}_{2} \mathrm{O}_{2}$ [11], are used in addition with ultrasound during the treatment of industrial effluents, which were proven to be effective for the treatment of biorefractory effluents.

The presence of activated carbon stimulate the production of active radicals in two simultaneous mechanisms; homogeneous and heterogeneous. In the absence of activated carbon the controlling mechanism would be homogeneous which produced less active radicals. Therefore, degradation of petrochemical wastewater was significantly increased by the addition of activated carbon. Also minimum amount of COD remaining is observed with $1 \mathrm{~g}$ activated carbon and $200 \mathrm{mg} / \mathrm{l}$ hydrogen peroxide as additives. This is because, the presence of hydrogen peroxide a key parameter for COD reduction in advanced oxidation process, depending on its concentration and nature of reductants. Hydrogen peroxide increases the formation rate of hydroxyl radicals in two ways. First, the reduction of $\mathrm{H}_{2} \mathrm{O}_{2}$ at the conduction band would produce hydroxyl radicals. Second, the self decomposition as a result of ultrasound irradiation would also produce hydroxyl radicals. Generally the degradation efficiency increases with $\mathrm{H}_{2} \mathrm{O}_{2}$ concentration until an optimal concentration is achieved.

The objective of the present study was to develop an innovative method for the treatment of petroleum refinery wastewater involving sono-chemical treatment using additives of such as activated carbon and $\mathrm{H}_{2} \mathrm{O}_{2}$

\section{Materials and Methods}

\section{Wastewater characterization}

Petroleum refinery wastewater was obtained from the central effluent treatment plant facility available at industrial estate, Chennai, India and it was stored in deep freezing unit. Initial value of $\mathrm{COD}, \mathrm{pH}$, suspended solids, dissolved solids, and total solids are $40000 \mathrm{mg} / \mathrm{l}, 5.4$, $1000 \mathrm{mg} / \mathrm{L}, 700 \mathrm{mg} / \mathrm{L}$ and $1700 \mathrm{mg} / \mathrm{L}$ respectively.

\section{Degradation experiments}

The ultrasonic irradiation was carried out in a sono-chemical

*Corresponding author: Qusay Jaffer Rasheed, Department of Chemical Engineering, A.C.Tech. Campus, Anna University Chennai, Chennai - 600025 , India, Tel: +919789019215; E-mail: engineerqusay@yahoo.com

Received January 03, 2011; Accepted March 01, 2011; Published April 22, 2011

Citation: Rasheed QJ (2011) Effect of Additive Agents on Sono-Degradation Petroleum Refinery Wastewater. Hydrol Current Res 2:109. doi:10.4172/21577587.1000109

Copyright: @ 2011 Rasheed QJ. This is an open-access article distributed under the terms of the Creative Commons Attribution License, which permits unrestricted use, distribution, and reproduction in any medium, provided the original author and source are credited. 
reactor (SAISONICS, Chennai, India) with a field frequency of 30 $\mathrm{KHz}$ and volume of $3000 \mathrm{ml}$ was used. The working volume was 500 $\mathrm{ml}$ and the sonication time was $30 \mathrm{~min}$. Chemical oxygen demand measurements were performed using COD digester (Open reflux method). All pH measurements were made by using digital $\mathrm{pH}$ meter.

\section{Experimental procedure}

In the present study, ultrasonic degradation was performed with $500 \mathrm{ml}$ of effluent. The effect of $\mathrm{pH}$ on degradation was carried out by varying the $\mathrm{pH}$ as $2,4,6,7,8,9$ and 10 . The $\mathrm{pH}$ of the effluent was adjusted using $0.1 \mathrm{M} \mathrm{H}_{2} \mathrm{SO}_{4}$ and $0.1 \mathrm{M} \mathrm{NaOH}$. The samples were collected for every $5 \mathrm{~min}$ and were centrifuged at $6000 \mathrm{rpm}$ for $10 \mathrm{~min}$. The supernatant was subjected to COD analysis and the optimum $\mathrm{pH}$ was arrived based on the maximum COD reduction.

The effect of addition of activated carbon and hydrogen peroxide during sonication was studied and in the present study.

Recycling of Activated Carbon Possibility of recycling activated carbon was enumerated, which has not been given attention in the literature. Initially, activated activated carbon was added into the effluent and the contents were sonicated. Then, the activated carbon was removed by filtration and added into distilled water (roughly equal to half of the volume of the original effluent). Then, it was sonicated for desired time to remove the adsorbed organics and destruct simultaneously. The technique followed is schematically represented in Figure 1.

\section{Analytical methods}

Chemical oxygen demand (COD) was determined by open reflux method [12] and the residual COD \% was calculated using the following equation:

$$
\text { residual COD } \%=100-\left(\frac{\text { initial } C O D-\text { final } C O D}{\text { initial COD }} \times 100\right)
$$

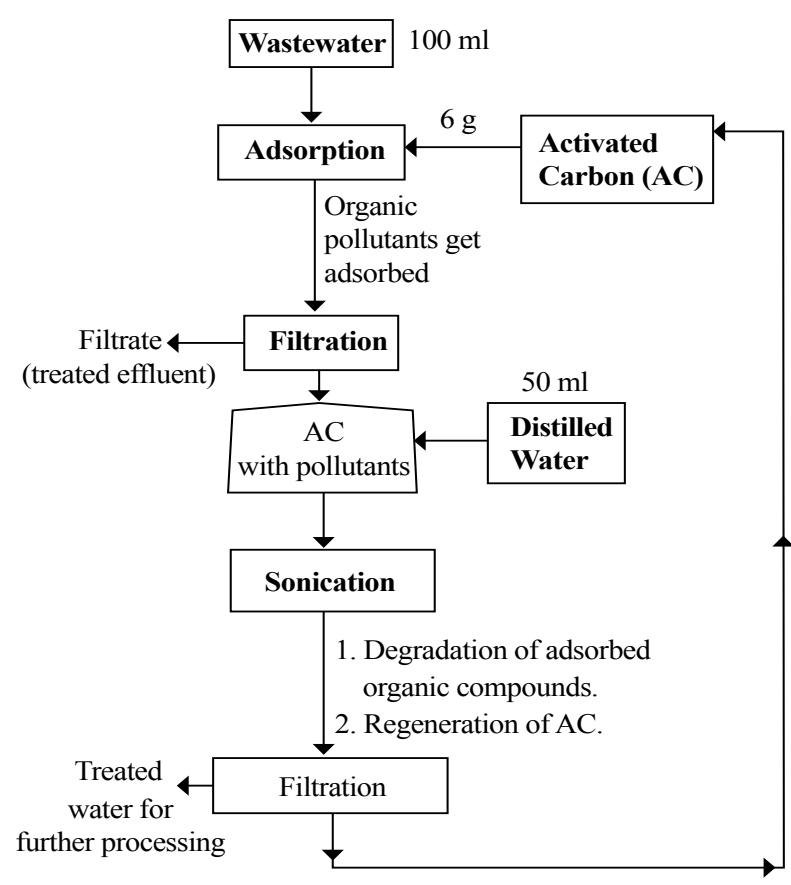

Figure 1:

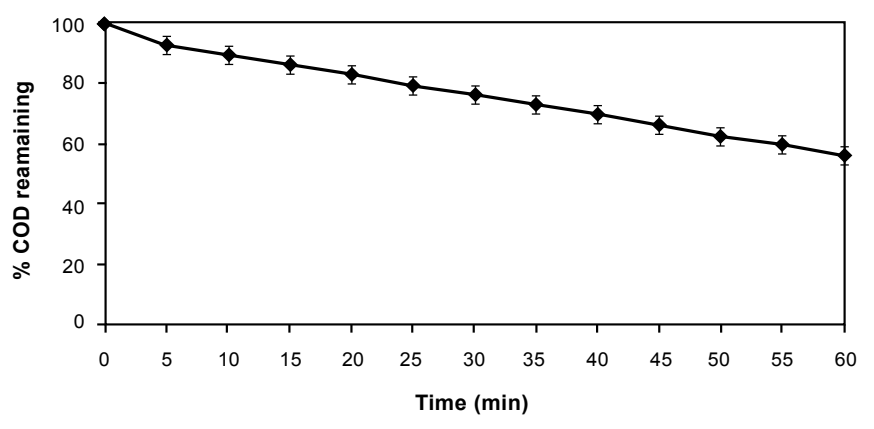

Figure 2: Effect of sonication time on \%COD remaining

\section{Results and Discussion}

\section{Sonolysis}

The effect of sonication time on \% COD remaining is shown in Figure 2. From the figure it can be seen that at the end of $60 \mathrm{~min}$ sonication the \% COD remaining was $56.666 \%$. Further increase in sonication time will definitely reduce the COD to a greater extend because the prolonged exposure of wastewater to ultrasound may enhance the generation of oxidative species. In elastic media such as air and most solids, there is a continuous transition as a sound wave is transmitted. In non-elastic media such as water and most liquids, there is continuous 3 tion as long as the amplitude or loudness of the sound is relatively low. As amplitude is increased the magnitude of the negative pressure in the areas of rarefaction eventually becomes sufficient to cause the liquid to fracture because of the negative pressure, causing a phenomenon known as cavitation. Cavitation bubbles are created at sites of rarefaction as the liquid fractures or tears because of the negative pressure of sound waves in the liquid. As the wave fronts pass, the cavitation bubbles oscillate under influence of positive pressure, eventually growing to an unstable size. Finally the violent collapse of the cavitation bubbles results in implosions, which causes radiation of shock waves from the sites of the collapse. The collapse and implosion of myriad cavitation bubbles throughout an ultrasonically activated liquid result in the effect commonly associated with ultrasound [1315]. Thus, sonochemical destruction of pollutants in aqueous phase generally occurs as the results of imploding cavitation bubbles and involves several reaction pathways and zones such as pyrolysis inside the bubble and/or at the bubble-liquid interface and hydroxyl radicalmediated reactions at the bubbleliquid interface and/or in the liquid bulk [16]. This is initiated by the hemolytic cleavage of water molecules by pyrolytic reactions, which may be represented as follows [17]:

$$
\begin{aligned}
& \mathrm{H}_{2} \mathrm{O} \rightarrow \mathrm{OH}+\mathrm{H} \\
& 2 \mathrm{OH}+2 \mathrm{H} \rightarrow \mathrm{H}_{2} \mathrm{O}_{2}+\mathrm{H}_{2}
\end{aligned}
$$

After the first reaction (Eqn. (2)), splitting of $\mathrm{H}_{2} \mathrm{O}$ into radicals, further reactions are depend on other oxidative radicals present inside the micro bubbles. The production rate of oxidants depends on the temperature and pressure prevailing at the time of bubble collapse. The lifetime of the micro bubbles is another important phenomenon that controls the production of oxidative species [8].

\section{Effect of Initial $\mathbf{p}^{\mathrm{H}}$}

The $\mathrm{pH}$ of the solution is one of the most important parameters affecting the degradation process. The effect of initial $\mathrm{pH}$ on the degradation of petrochemical wastewater is shown in Figure 3. The 
$\mathrm{pH}$ was varied between $2-10$ and the minimum $\%$ COD remaining obtained at the end of $60 \mathrm{~min}$ was $6.666 \%$. As the $\mathrm{pH}$ increases, the number of negatively charged sites increases [18]. A negatively charged surface site on activated carbon favors the adsorption of wastewater cations due to the electrostatic attraction. Hence, the degradation of the wastewater was increased. The studies also indicated that the degradation efficiency increased when the $\mathrm{pH}$ was decreased.

\section{Effect of additives}

The influence of addition of activated carbon in different concentrations $(0.5,1,1.5$ and $2 \mathrm{gm})$ and the effect of adding activated carbon with hydrogen peroxide (50,100, 150 and $200 \mathrm{mg} / \mathrm{l}$ ) on sonochemcal degradation of effluent at $\mathrm{pH} 10$ was studied. The results obtained are presented in Figure 4. At the end of $50 \mathrm{~min}$ of sonication, $\%$ COD remaining was found to be 6.666 for $2 \mathrm{gm}$ activated carbon at $\mathrm{pH} 10$. The hydrogen peroxide $(50,100,150$ and $200 \mathrm{mg} / \mathrm{l})$ respectively in Figure 5. With $2 \mathrm{gm}$ of activated carbon as a sole additive, the \% COD remaining was found to be 6.666 at the end of $30 \mathrm{~min}$. The activated carbon plays a major role as a catalyst for the sono chemical degradation of organic pollutants present in the wastewater.

\section{Effect of additives on adsorption}

Therefore, to investigate the recycle of activated carbon, $100 \mathrm{ml}$ of wastewater was added with $6 \mathrm{~g}$ of activated carbon and the contents were shaken well for the complete adsorption of organic pollutants into activated carbon. Then, the activated carbon containing pollutants was added into distilled water (volume equal to half of the amount

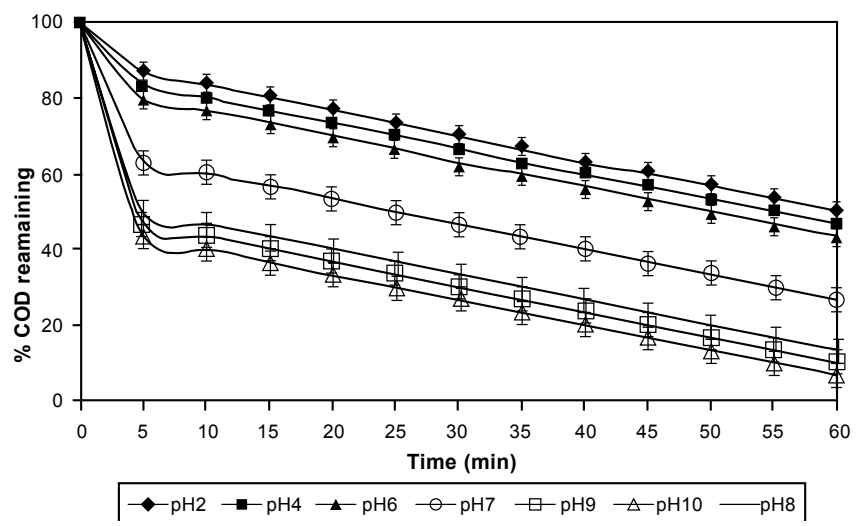

Figure 3: Effect of initial $\mathrm{pH}$ - on \%COD remaining after 60 min of sonication.

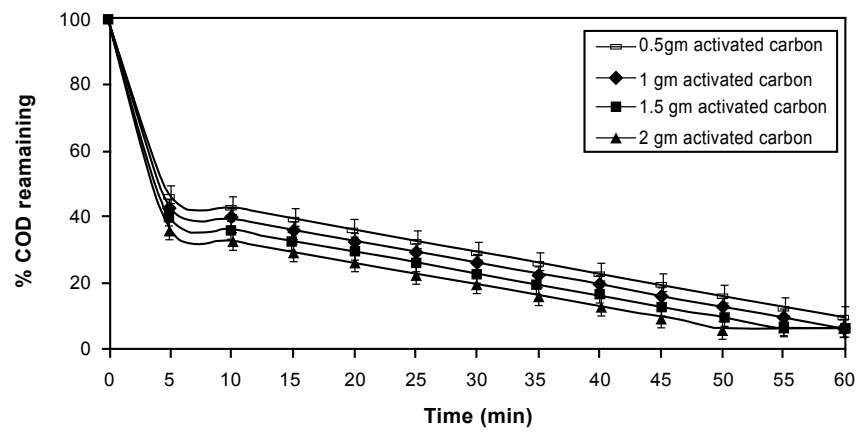

Figure 4: Effect of constant time on \%COD remaining during adsorpitive removal of organics.

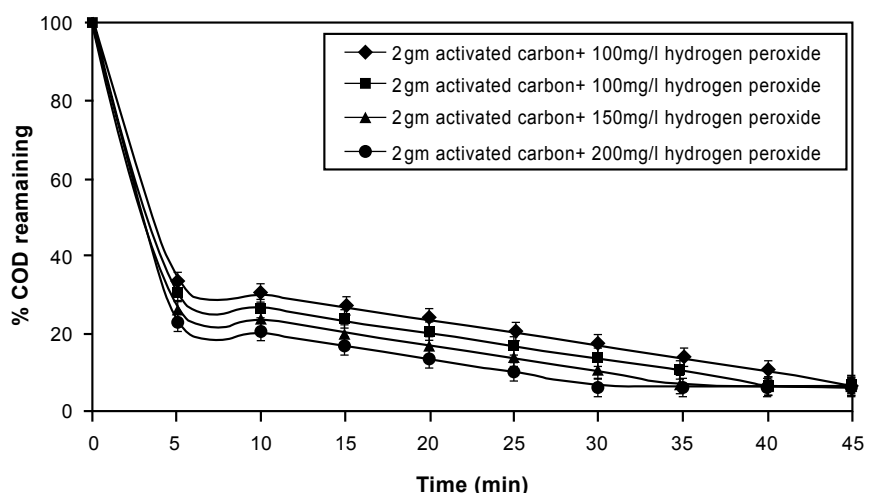

Figure 5: Effect of sonication time on \%COD remaining in presence of additives.

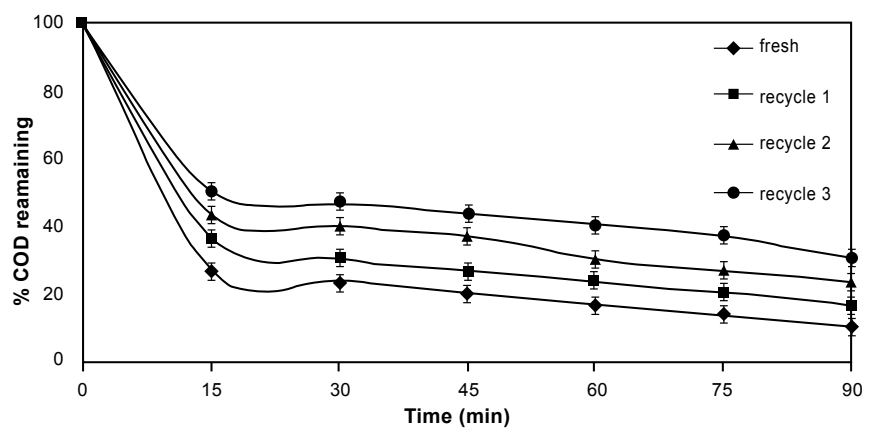

Figure 6: Effect of soinication time on \%COD remaining with recycled activaties carbon.

of wastewater originally taken). The entire contents were sonicated to completely destruct the organics present. After that the contents were filtered and then the activated carbon was recycled. At the end of 90 min of sonication, the \% COD remaining was increases when the recycling of activated carbon increases Figure 6.

\section{Conclusions}

The results obtained in this study show that sonolysis in the presence of $\mathrm{H} 2 \mathrm{O} 2$ and activated carbon is an effective technique for the degradation of petrochemical wastewater. The effect of various initial $\mathrm{pH}$ was studied and it was observed that at $\mathrm{pH} 10$, efficient degradation was occurred, generally the degradation efficiency increases with activated carbon $+\mathrm{H}_{2} \mathrm{O}_{2}$ concentration until an optimal concentration is achieved, activated carbon as sole additive for sonolysis process, $2 \mathrm{gm}$ of activated carbon with $200 \mathrm{mg} / \mathrm{l}$ of $\mathrm{H} 2 \mathrm{O} 2$ that the better degradation was found in the $\mathrm{pH} 10$. The combination of two additives showed effective COD removal [12]. A novel method for the recycle of activated carbon was proposed and it was found that the recycled carbon efficiently removed the organics present in the effluent.

\section{References}

1. Wang XK, Yao Z, Wang J, Guo W, Li G (2008) Degradation of reactive brilliant red in aqueous solution by ultrasonic cavitation, Ultrasonics Sonochemistry 15 43- 48.

2. Barros AL, Pizzolato TM, Carissimi E, Schneid IAH (2006) Decolorizing dye wastewater from the agate industry with Fenton oxidation process. Minerals Engineering 19: 87-90.

3. Joseph S, Marjorie L, Meyer Diane M, McKnight (2007) Photo oxidation of wetland and revering dissolved organic matter: altered copper complexation and organic composition. Hydrobiologia 579: 95-113. 
Citation: Rasheed QJ (2011) Effect of Additive Agents on Sono-Degradation Petroleum Refinery Wastewater. Hydrol Current Res 2:109. doi:10.4172/2157-7587.1000109

4. Carini G, Angelo GD, Tripodo G, Bartolotta A, Di Marco D, et al. (2005) Ultrasonic relaxations, an harmonicity, and fragility in lithium borate glasses. Phys Rev B 72.

5. Carlesi Jara C, Fino D, Specchia V, Saracco G, Spinelli P (2007) Electrochemica removal of antibiotics from wastewaters, Applied Catalysis B: Environmental 479-487.

6. Gonze E, Pilot S, Valette E, Gonthier Y, Bernis A (2003) Ultrasonic treatment of an aerobic activated sludge. Cheml Eng Process 42: 965- 975.

7. Chu CP, Lee DJ, Chang BV, Liao CS (2001) Observations on changes in ultrasonically treated waste activated sludge. Water Res 35: 1038- 1046.

8. Vajnhandl S, Majcen A, Marechal L (2007) Case study of the sonochemical decoloration of textile azo dye Reactive Black 5. J Hazard mater 141: 329-335.

9. Kidak R, Ince NH (2007) Catalysis of advanced oxidation reactions by ultrasound: A case study with phenol, J Hazard mater 146: 630-635.

10. Li M, Li J-T, Sun H-W (2008) Sonochemical decolorization of acid black 210 in the presence of foliated graphite. Ulrason sonochem, 15: 37-42.

11. Abbasi M, AsI NR (2008) Sonochemical degradation of Basic Blue 41 dye assisted by nano $\mathrm{TiO}_{2}$ and $\mathrm{H}_{2} \mathrm{O}_{2} \mathrm{~J}$ Hazard mater 153: 942-947.

12. PHA, AWWA and WEF, Standard methods for the examination of water and wastewater, $19^{\text {th }}$ ed. Washington D.C (1995)

13. Scherba G, Weigel RM, Obrien WD (1991) Quantitative assessment of the germicidal efficacy of ultrasonic energy. App Environ Microbiol 57: 2079-2084.

14. Hua I, Hoffmann MR (1997) Optimization of ultrasonic irradiation as advanced oxidation technology. Environ Sci Technol, 31: 2237-2243.

15. Kalumuk KM (2003). Remediation and disinfection of water using jet generated cavitation. 5th International Symposium on Cavitation (CAV 2003), Osaka Japan.

16. Vassilakis C, Pantidou A, Psillakis E, Calogerakis N, Mantzavinos D (2004) Sonolysis of natural phenolic compounds in aqueous solutions: degradation pathways and biodegradability. Wat Res 38: 3110-3118.

17. Crittenden JC, Trussell RR, Hand DW, Tchobanglouse G (2005). Water treatment principles and design. 2nd Ed, John Wily and Sons.

18. Jiang Y, Petrier $\mathrm{CH}$, Waite TD (2002) Effect of $\mathrm{pH}$ on the ultrasonic degradation of ionic aromatic compounds in aqueos solution. Ultrason Sonochem 9: 163-68. 